\section{Epidemiological changes and financial consequences of hypertension in Latin America: implications for the health system and patients in Mexico}

\author{
Cambios epidemiológicos y consecuencias \\ financieras de la hipertensión en América Latina: \\ implicaciones para el sistema de salud y los \\ pacientes en México
}

\author{
1 Instituto Nacional de Salud \\ Pública, Cuernavaca, México. \\ Correspondence \\ A. Arredondo \\ Instituto Nacional de Salud \\ Pública. \\ Av. Universidad 655, \\ Cuernavaca, Morelos - 62508, \\ México. \\ aarredon@insp.mx
}

\begin{abstract}
The aim of this study was to assess the costs and financial consequences of epidemiological changes in hypertension in México. The cost evaluation method to estimate costs was based on instrumentation techniques. To estimate the epidemiological changes and expected cases of hypertension in 2010-2012, three probabilistic models were constructed according to the BoxJenkins technique. Comparing the economic impact, from 2010 to 2012 there will be a 24\% increase in financial requirements $(p<0.05)$. The total cost of hypertension in 2011 will be US\$ 5,733,350,291, including US\$2,718,280,941 in direct costs and US\$3,015,069,350 in indirect costs. If the risk factors and various healthcare models remain unaltered in the institutions analyzed here, the financial consequences will have a major impact on users' pockets, followed by social security providers and public healthcare providers. The authors suggest a revision in the planning, organization, and allocation of resources, particularly programs for health promotion and prevention of hypertension.
\end{abstract}

Financial Management; Costs and Cost Analysis; Hypertension
Armando Arredondo 1

Alexis Zuñiga 1

\section{Introduction}

Hypertension is a health problem that requires an integrated approach. The increase in the incidence of hypertension has not been solved only by enhanced efforts to provide treatments or by allocating the necessary resources for them. The increase in the incidence of hypertension is expected to continue 1. In Mexico, prevalence of hypertension increased from $26.6 \%$ in 1993 to $30.8 \%$ in 20062 . The disease clearly impacts not only mortality, but also morbidity and quality of life. Morbidity related to hypertension represents an enormous burden for patients and their families, as well as for the health system and society in general 3 .

The predicted and observed epidemiological changes in the incidence of hypertension will generate constant increases in the demand for health services ${ }^{4}$. Economic changes represent a heavy economic burden on health systems in the medium and long term. To date, few detailed studies have addressed the financial consequences of epidemiological changes in hypertension in Latin America, and more specifically in Mexico. Thus, there is no knowledge on the costs that would allow developing resource allocation patterns for more efficient use of expenditures on hypertension.

The constantly increasing costs of medical care, the unknown costs of outpatient and 
inpatient case management, and the uncertain economic resources needed to meet future demands for health services justify the urgent and targeted development and use of indicators for such changes in demand and the costs of case management in the future 5 .

Therefore, this brief paper aims to present evidence of unknown economic indicators of epidemiological changes in chronic non-communicable diseases. We particularly highlight the implications of the economic impact of hypertension on users and providers of health services as one of the main challenges for health planners in resource allocation for hypertension, with greater equity and efficiency.

\section{Methods}

The class of auto-regressive and moving average models includes the Box-Jenkins method, developed as a probabilistic model for the expected number of cases of chronic non-communicable diseases. This method was chosen for three reasons: (1) observations in the case of chronic diseases tend to be highly correlated; (2) the model included the availability of data with the quality and quantity required to implement this forecasting method; and (3) it is one of the most widely validated and utilized models for providing greater certainty in projections in the short and medium term for the analysis of public health problems.

The models for predicting demand here refer to the period 2010-2012. The estimation method was based on the Box-Jenkins methodology for health forecasts 5,6. The following steps were taken in the development of the probabilistic models:

- Step 1. Identification: (a) identification of the tentative model for the time series to be used in the prediction; (b) verification of data quality and number of observations; and (c) analysis of autocorrelation of historical observations.

- Step 2. Estimation: (a) determination of estimates for the parameters, using least squares and (b) application of an iterative procedure searching for a sum of squares function, previously specifying the preliminary estimates of the unknown parameters.

- Step 3. Diagnostic check: (a) adequacy test after fitting the data to the models; (b) analysis of the difference between the observed and expected results; and (c) application of the Box-Pierce chi-square test.

- Step 4. Prediction: (a) selection and design of the definitive model; (b) data processing; and (c) prediction of the future values in the time series.
The resulting models for estimating the expected demand from hypertension was a model with an average movement operator (order 1). To calculate financial consequences caused by changes in epidemiological profile and demand by type of institution, an inflationary index projected to 2011 was developed and applied, based on the consumer price index (as defined by the Banco de México).

For estimations of the direct and indirect costs of hypertension, we took 2011 as a cut-off year, since it corresponds to one-half of the projected time period. Estimates were made by consensus with clinical experts in management of hypertension in different areas of the health sector. Direct costs of case management were determined from production functions, combination of inputs, quality standards, and costs of inputs for each sector.

Indirect costs were determined using the human capital model developed for Latin America 7, and models were designed to include three categories of monetary costs (death, permanent disability, and temporary disability) attributable to hypertension in three public institutions. To estimate mortality costs, we calculated the indirect cost of premature mortality due to hypertension. We used the number of premature deaths from the general mortality records in vital statistics, by type of institution 8,9,10. Causes of death considered in the study included: myocardial infarction, cerebral hemorrhage, and cardiac insufficiency. Costs of premature mortality were obtained by multiplying the total accumulated annual life years lost among individuals younger than 65 years, multiplied by per capita GNP, thereby obtaining the total indirect costs attributable to premature mortality.

To calculate permanent disability, the "years of productive life lost" indicator was used, multiplied by per capita GNP estimated for 2011 . Temporary disability costs were obtained using the National Survey of Chronic Diseases 11. For each institution, the mean number of days with disability related to hypertension was used, multiplied by the estimated number of temporary disabilities for 2011; this number was multiplied by the daily cost of lost productivity as a function of estimated per capita GNP for 2011.

\section{Results}

The results shown in Tables 1 and 2 include new evidence that complements other findings published in 2002, 2006, and 2009 12,13,14, originating from a study on annual monitoring of costs and financial consequences of epidemiological 
changes in chronic non-communicable diseases in Mexico. Comparison of the economic impact in 2010 and the forecast for 2012 ( $\mathrm{p}<0.05)$ shows an expected $24 \%$ increase in financial requirements (Table 1). Total predicted cost of hypertension in 2011 is US\$ 5,733,350,291 (Table 2), including US\$2,718,280,941 in direct costs and US\$ $3,015,069,350$ in indirect costs. Total expected direct costs are US\$ 842,711,773 for the Ministry of Health, serving the uninsured population, US\$1,966,632,166 for the insured population (the Mexican Institute of Social Security and the Institute of Social Security and Services for State Workers), and US\$2,924,066,352 as out-of-pocket costs. Nephropathy is the largest single contributor to total treatment costs (US\$ $941,884,606)$, followed by nonfatal myocardial infarction (US\$ 428,129,175) and nonfatal stroke (US\$ 342,502,928).

Total costs included $47 \%$ direct costs and $53 \%$ indirect costs. The results for the four categories of estimated direct costs were: consultations and diagnoses, $12 \%$; drugs, $14 \%$; hospitalizations, $11 \%$; and complications, $63 \%$. The breakdown of total costs of complications was: nephropathy, $55 \%$; nonfatal myocardial infarction, $25 \%$; and nonfatal stroke, $20 \%$. Results for the three estimated categories of indirect costs were: death, $15 \%$; permanent disability, $74 \%$; and temporary disability, 11\% (Table 2).

\section{Discussion}

In terms of the impact of observed epidemiological changes on health demand for in-hospital and outpatient services for 2010-2012, an increase in costs is expected (although greater among the insured population versus the uninsured).

As for direct costs to patients, the high outof-pocket expenses for treatment of hypertension and the implications for equity and access to healthcare in Mexico are particularly troublesome. For every US\$ 100 spent on hypertension in Mexico, approximately US\$ 51 comes from household/family income. This represents a heavy social burden with a considerable effect on health expenditures in the country, since hypertension is an expensive disease and a high public health priority.

In terms of expected costs for the insured versus uninsured, the differences in results are mainly due to three factors: the higher costs of inputs in social security institutions; the larger population seeking care for hypertension in institutions providing uninsured care; and differences in quality of care standards and input mix.

Although these indirect costs do not have a direct impact on the health budget in terms of cost and social impact, they do represent a heavy burden for society in general, mainly from lost productivity due to premature death and temporary or permanent disability. Estimated financial

Expected direct, indirect, and total costs (in US\$) attributable to hypertension for the years 2010, 2011, and 2012 in Mexico.

\begin{tabular}{lccc}
\hline Item & 2010 & $\mathbf{2 0 1 1}$ & $\mathbf{2 0 1 2}$ \\
\hline Direct costs & & & \\
$\quad$ Consultations/Diagnosis & $293,574,600$ & $326,194,000$ & $371,861,160$ \\
Drugs & $342,503,542$ & $380,559,492$ & $433,837,820$ \\
Hospitalization & $269,109,666$ & $340,872,243$ \\
Nephropathy & $847,696,145$ & $299,010,740$ & $1,073,748,451$ \\
Nonfatal myocardial infarction & $385,316,257$ & $941,884,606$ & $488,067,259$ \\
Nonfatal stroke & $308,252,635$ & $428,129,175$ & $390,453,337$ \\
Total direct & $2,446,452,847$ & $342,502,928$ & $3,098,840,273$ \\
Indirect costs & & $2,718,280,941$ & $515,576,258$ \\
Death & $407,033,888$ & & $2,543,513,356$ \\
Permanent disability & $2,008,036,860$ & $372,259,876$ & $3,089,444$ \\
Temporary disability & $298,491,666$ & $2,231,152,067$ & $3,437,179,059$ \\
Total indirect & $2,713,562,415$ & $331,657,407$ & $6,536,019,332$ \\
Total costs & $5,160,015,262$ & $3,015,069,350$ & $5,733,350,291$ \\
\end{tabular}

Source: Arredondo et al. 15; 1999-2009. Update of probabilistic models, January 2010.

Exchange rate: January 2010, 1 US $\$=12.35$ Mexican $\$$.

$95 \% \mathrm{Cl}$ Box-Pierce statistical test $(p<0.05)$. 
Expected direct, indirect, and total costs (in US\$) attributable to hypertension for healthcare providers and users in the year 2011 in Mexico.

\begin{tabular}{|c|c|c|c|c|c|c|}
\hline \multirow[t]{2}{*}{ Item } & \multicolumn{6}{|c|}{ Healthcare service providers and users } \\
\hline & SSA & IMSS & ISSSTE & Users & Total & $\%$ \\
\hline \multicolumn{7}{|l|}{ Direct costs } \\
\hline Consultations/diagnosis & $47,939,568$ & $79,937,235$ & $31,958,327$ & $166,358,870$ & $326,194,000$ & 5.68 \\
\hline Drugs & $55,929,494$ & $93,260,105$ & $37,284,713$ & $194,085,180$ & $380,559,492$ & 6.63 \\
\hline Hospitalization & $43,944,603$ & $73,275,796$ & $29,295,132$ & $152,495,209$ & $299,010,740$ & 5.21 \\
\hline Nephropathy & $138,425,501$ & $230,818,761$ & $92,279,666$ & $480,360,678$ & $941,884,606$ & 16.42 \\
\hline Nonfatal myocardial infarction & $62,920,682$ & $104,917,618$ & $41,945,302$ & $218,345,573$ & $428,129,175$ & 7.46 \\
\hline Nonfatal stroke & $50,336,546$ & $83,934,095$ & $33,556,242$ & $174,676,045$ & $342,502,928$ & 5.97 \\
\hline Total direct & $399,496,394$ & $666,143,610$ & $266,319,382$ & $1,386,321,555$ & $2,718,280,941$ & 47.42 \\
\hline \multicolumn{7}{|l|}{ Indirect costs } \\
\hline Mortality & $66,482,307$ & $110,803,845$ & $44,321,538$ & $230,652,186$ & $452,259,876$ & 7.88 \\
\hline Permanent disability & $327,979,381$ & $546,632,302$ & $218,652,920$ & $1,137,887,464$ & $2,231,152,067$ & 38.91 \\
\hline Temporary disability & $48,753,691$ & $81,256,153$ & $32,502,416$ & $169,145,147$ & $331,657,407$ & 5.78 \\
\hline Total indirect & $443,215,379$ & $738,692,300$ & $295,476,874$ & $1,537,684,797$ & $3,015,069,350$ & 52.58 \\
\hline Total costs & $842,711,773$ & $1,404,835,910$ & $561,796,256$ & $2,924,006,352$ & $5,733,350,291$ & 100.00 \\
\hline
\end{tabular}

IMSS: Mexican Institute for Social Security; SSA: Health Secretariat, Mexican Ministry of Health; ISSSTE: Institute for Social Security and Services for State Workers

Source: Arredondo et al. 15; 1999-2009. Update of probabilistic models, January 2010.

Exchange rate: January 2010, 1 US\$ $=12.35$ Mexican $\$$.

$95 \% \mathrm{Cl}$ Box-Pierce statistical test $(p<0.05)$

requirements constitute the fundamental basis of information for strategic planning. Given the financial consequences of expected epidemiological changes, it is essential to both invest more financial resources and implement health prevention strategies.

As for implications for the health system and patients, we propose the following:

The evidence on changes in costs and the demand for healthcare for patients with hypertension can be used as a reference for resource allocation for hypertension in different types of public institutions. With knowledge of likely financial requirements, each institution could then effectively and efficiently earmark the necessary resources for promotion, prevention, treatment, and rehabilitation.

A consequence of the implementation of cost-monitoring systems is the design and application of strategies for cost containment for weight-by-cost items. For example, knowing that the cost of medicines is high, each institution needs to review its agreements with the pharmaceutical industry on consolidated purchases of drugs for hypertension.

Development of economic indicators would enable the design of patterns of resource allocation based on efficiency criteria vis-à-vis clini- cal, epidemiological, economic, and administrative issues. Each institution could develop models for resource distribution according to the expected changes in costs and epidemiological factors.

As a "Citizen Observatory of Hypertension", social organizations could suggest and develop programs to monitor the costs of hypertension in different public and private healthcare institutions. The Observatory could serve to verify how much is being spent to manage hypertension, including itemized expenditures.

Knowledge of the relative weight of management of hypertension based on annual family income, as well as precise knowledge of the cost of complications for users, should be made available through a bulletin sent to patients, their families, and the community as a whole. Knowledge of the high costs of hypertension per family could lead to greater self-awareness and efforts to avoid the complications of the illness.

A list of recommendations is needed to promote improvement of self-care and control of risk factors, besides raising awareness on the benefits of such measures and, more importantly, to avoid falling into a catastrophic cost situation due to hypertension (with an impact greater than $30 \%$ on family income). 
Within the field of the healthcare services and research and development in human resources, our results emphasize the importance of health evaluation and promotion, with important changes in the social aspects of hypertension as a high-priority public health problem. Treatment of hypertension should be ap- proached from an integrated perspective (clinical, economic, epidemiological, and organizational). An integrated approach to hypertension requires developing indicators of clinical and economic efficiency, expected epidemiological changes, and demands for medical care and services.

\section{Resumen}

El objetivo fue identificar los costos y las consecuencias financieras de cambios epidemiológicos referentes a la hipertensión en México. El método de evaluación de los costos, para estimar los costos directos e indirectos, se basó en técnicas de instrumentación y de consenso. Para estimar los cambios epidemiológicos y de casos esperados para el período 2010-2012, tres modelos probabilísticos se construyeron de acuerdo a la técnica de Box-Jenkins. Al comparar el impacto económico en el 2010 frente a $2012(p<0.05)$, hay un incremento del $24 \%$ de las necesidades financieras. El importe total para la hipertensión en 2011 será de US\$ 5.733.350.291. Se incluyen US\$2.718.280.941 en costos directos y US\$3.015.069.350 en costos indirectos. Si los factores de riesgo y los modelos de atención a la salud permanecen sin cambios, las consecuencias financieras serían de mayor impacto para los bolsillos de los usuarios, siguiendo en orden de importancia, los proveedores de seguridad social y los proveedores de asistencia pública.

Administración Financiera; Costos y Análisis de Costo; Hipertensión

\section{Contributors}

A. Arredondo contributed to the study design and coordinated all the phases of the article. A. Zuñiga contributed to the design of the models and analysis of the results. Both authors wrote and revised the text. 


\section{References}

1. Pan American Health Organization. Health in the Americas-2002. Washington DC: Pan American Health Organization; 2002.

2. Secretaría de Salud. Encuesta nacional de nutrición y salud: hipertensión. 3ra Ed. México DF: Secretaría de Salud; 2009.

3. Instituto Nacional de Salud Pública. Métodos de estimación de cambios epidemiológicos y demanda esperada de enfermedades crónico-degenerativas. Cuernavaca: Instituto Nacional de Salud Pública; 2010. (Informe Técnico de Memoria Metodológica).

4. Arredondo A, Barceló A. The economic burden of out-of-pocket medical expenditures for patients seeking diabetes care in Mexico. Diabetologia 2007; 50:435-6.

5. Altkin M, Francis B, Hinde J, Anderson D. Statistical modeling in GLIM. New York: Oxford University Press; 2000.

6. World Health Organization. Guidelines to assess the social and economic impact consequences of the diseases. Geneva: World Health Organization; 2009.

7. Barcelo A, Aedo C, Rajpathak S, Robles S. The cost of diabetes in Latin America and the Caribbean. Bull World Health Organ 2003; 81:19-27.

8. García C, Thorogood M, Reyes S, Salmerón J, Durán $\mathrm{C}$. The prevalence and treatment of hypertension in the elderly population. Salud Pública Méx 2001; 4:415-20.
9. Secretaría de Salud. Salud México. Prevención y control de enfermedades: programa para hipertensión arterial. v. 1. México DF: Secretaría de Salud; 2004.

10. Secretaría de Salud. Boletín del Sistema Único de Información Epidemiológica 2010; 22:3-4.

11. Secretaría de Salud. Informe técnico de resultados de la Encuesta Nacional de Enfermedades Crónicas. México DF: Secretaría de Salud; 1998. (DGE/ Documento, 12).

12. Villarreal E, Matew-Quiroz A. Costo de la atención de la hipertensión arterial y su impacto en el gasto en salud en México. Salud Pública México 2002; 44:7-13.

13. Arredondo A, Zuñiga A. Epidemiological changes and economic burden of hypertension in Latin America: evidence from Mexico. Am J Hypertens 2006; 19:553-9.

14. Arredondo A, Servan E. Costs of epidemiological changes in chronic diseases in Mexico. In: Hofmann BR, editor. Health care costs: causes, effects and control. London: Nova Publishers; 2009. p. 128-44.

15. Arredondo A, Zuñiga A, Alvarez C. Costos y consecuencias financieras del cambio en el perfil epidemiológico en México. México DF: Instituto Nacional de Salud Pública/University of Montreal/International Development Research Centre; 2010.

Submitted on 22/Feb/2011

Final version resubmitted on 18/Aug/2011 Approved on 13/Sep/2011 